Editors' Note: Most physicians can relate to the challenges of the direct funduscopic examination, likely including the emergency department (ED) physicians included in the study by Thulasi et al. As the authors highlight, the ED physicians picked up $0 \%$ of fundus abnormalities on direct funduscopic examination vs $46 \%$ when reading fundus photographs. This seems argument enough for more widespread use of this technology. Drs. Shubhakaran et al. expand on the topic by describing the use of the funduscopic examination in infectious disease.

Megan Alcauskas, MD, and Robert C. Griggs, MD

\section{CHILDHOOD OBESITY AND RISK OF PEDIATRIC MULTIPLE SCLEROSIS AND CLINICALLY ISOLATED SYNDROME}

Julia Pakpoor, Oxford; Jina Pakpoor, Cambridge:

Langer-Gould et al. ${ }^{1}$ demonstrated a strong association between pediatric multiple sclerosis (MS)/clinically isolated syndrome (CIS) risk and weight. This association may be explained by vitamin $\mathrm{D}$ deficiency as it is widely recognized as an environmental risk factor for MS. Obese adolescents have been shown to be at particular risk of vitamin D deficiency. ${ }^{2}$ Vitamin D is a fat-soluble vitamin with a reduced bioavailability in obese individuals due to its sequestration in body fat. ${ }^{3}$ A US study of 68 multiethnic obese adolescents found low vitamin D status in 100\% of girls and $91 \%$ of boys, ${ }^{4}$ greater than in adolescents in general. ${ }^{5} \mathrm{We}$ postulate that the association between weight and risk of MS/CIS may be a consequence of greater vitamin D deficiency in obese individuals, which confers increased MS/CIS risk. Less likely, there may be a shared underlying risk factor in vitamin D deficiency. Elucidating the mechanism of this association and particularly the role of (preventable) vitamin D deficiency may become an important public health issue in light of the emerging childhood obesity epidemic which, as the authors note, may predict a rising incidence of pediatric MS/CIS.

(C) 2013 American Academy of Neurology

1. Langer-Gould A, Brara SM, Beaber BE, Koebnick C. Childhood obesity and risk of pediatric multiple sclerosis and clinically isolated syndrome. Neurology 2013;80: 548-552.
2. Smotkin-Tangorra M, Purushothaman R, Gupta A, Nejati G, Anhalt $\mathrm{H}$, Ten S. Prevalence of vitamin D insufficiency in obese children and adolescents. J Pediatr Endocrinol Metab 2007;20:817-823.

3. Wortsman J, Matsuoka LY, Chen TC, Lu Z, Holick MF. Decreased bioavailability of vitamin D in obesity. Am J Clin Nutr 2000;72:690-693.

4. Harel Z, Flanagan P, Forcier M, Harel D. Low vitamin D status among obese adolescents: prevalence and response to treatment. J Adolesc Health 2011;48:448-452.

5. Kumar J, Muntner P, Kaskel FJ, Hailpern SM, Melamed ML. Prevalence and associations of 25-hydroxyvitamin D deficiency in US children: NHANES 2001-2004. Pediatrics 2009;124:e362-370.

\section{NONMYDRIATIC OCULAR FUNDUS PHOTOGRAPHY AMONG HEADACHE PATIENTS IN AN EMERGENCY DEPARTMENT}

Khichar Shubhakaran, Rekha Jakhar Khichar, Jodhpur, India: Thulasi et al. ${ }^{1}$ studied the importance of funduscopic examination in patients with headache. Fundus findings are well-described in noncommunicable diseases such as hypertension, diabetes mellitus, and congenital and hereditary metabolic disorders but not in infectious diseases. ${ }^{2}$ Retinopathy has been reported in some infectious diseases like malaria, infective endocarditis, cysticercosis, HIV, and dengue. ${ }^{2,3}$ Fundus findings would aid clinicians in rural settings or underdeveloped environments in reaching a diagnosis depending on the prevalent disease in that area.

Starting in 1879, ocular changes in malaria have been reported, but with varying results. ${ }^{2}$ In a prospective study, we found that ophthalmoscopic abnormalities were not necessarily associated with mortalityexcept disc pallor-but they may indicate worse prognosis. ${ }^{4}$ Of course, such fundus findings may give a clue to the diagnosis of malaria in endemic areas, but similar findings were also described in a smaller study regarding dengue hemorrhagic fever. ${ }^{2}$

Retinopathy in infectious diseases is an index of complications like hemorrhagic tendency or anemia. Further larger randomized trials are needed to determine their importance, but this type of examination may still be helpful in places where resources are scarce.

Author Response: Beau B. Bruce, Valerie Biousse, Nancy J. Newman, Atlanta: We thank Shubhakaran 
et al. for their comments on our article $^{1}$ and agree that funduscopic examination is important for the overall physical examination and that direct ophthalmoscopy is not performed as often or as accurately as it should be. ${ }^{5}$ We have shown that nonmydriatic fundus photography is a relatively fast, clinically feasible alternative to direct ophthalmoscopy even in a busy ED setting. ${ }^{6}$ We also found that emergency physicians themselves - without specific training in reading fundus photographs - had substantially better sensitivity for abnormalities when reading fundus photographs than when using the direct ophthalmoscope (46\% of abnormalities identified with fundus photographs vs $0 \%$ with direct ophthalmoscopy) and that photographs were often useful even when normal. ${ }^{7}$ Combining digital photographs with mobile technologies, such as smartphones, promises better ophthalmologic care for a wide variety of neurologic and medical conditions in resource-scarce settings. ${ }^{8}$ Increased use of nonmydriatic photography will help to reestablish the importance of the ocular fundus examination in the diagnostician's armamentarium.

(C) 2013 American Academy of Neurology
1. Thulasi P, Fraser CL, Biousse V, Wright DW, Newman NJ, Bruce BB. Nonmydriatic ocular fundus photography among headache patients in an emergency department. Neurology 2013;80:432-437.

2. Shubhakaran K, Jakhar R. Ocular changes in infectious diseases. J Assoc Physicians India 2005;53:913-914.

3. Mehta S. Ocular lesions in severe dengue haemorrhagic fever. J Assoc Physicians India 2005;53:656-657.

4. Kochar DK, Shubhakaran K, Kumawat BL, Thanvi I, Joshi A, Vyas SP. Ophthalmoscopic abnormalities in adults with falciparum malaria. Q J Med 1998;91:845852.

5. Bruce BB, Lamirel C, Wright DW, et al. Nonmydriatic ocular fundus photography in the emergency department. N Engl J Med 2011;364:387-389.

6. Bruce BB, Lamirel C, Biousse V, et al. Feasibility of nonmydriatic ocular fundus photography in the emergency department: phase I of the FOTO-ED study. Acad Emerg Med 2011;18:928-933.

7. Bruce BB, Thulasi P, Fraser CL, et al. Diagnostic accuracy and use of nonmydriatic ocular fundus photography by emergency physicians: phase II of the FOTO-ED study. Ann Emerg Med Epub 2013 Feb 20.

8. Lamirel C, Bruce BB, Wright DW, Newman NJ, Biousse V. Nonmydriatic digital ocular fundus photography on the iPhone 3G: the FOTO-ED study. Arch Ophthalmol 2012;130:939-940.

\section{CORRECTION}

Characteristic distributions of intracerebral hemorrhage-associated diffusion-weighted lesions

In the article "Characteristic distributions of intracerebral hemorrhage-associated diffusion-weighted lesions" by Auriel et al. (Neurology ${ }^{\circledR}$ 2012;79:2335-2341), there is an error in the fourth paragraph of the Discussion. The second sentence should read "In the current study, we observed 13 lesions (on 10 positive scans) among 82 scans performed without triggering clinical event, yielding estimates for the overall incidence of these lesions between 4.1 per year (if the lesions are assumed to remain visible as long as 14 days $^{11}$ ) and 8.3 per year (if assumed to remain visible only 7 days).” The authors regret the error. 


\section{Neurology}

\section{Nonmydriatic ocular fundus photography among headache patients in an emergency department}

Khichar Shubhakaran and Rekha Jakhar Khichar Neurology 2013;81;1366-1367

DOI 10.1212/01.wnl.0000436284.64959.67

\section{This information is current as of October 7, 2013}

\section{Updated Information \& Services}

References

Permissions \& Licensing

Reprints including high resolution figures, can be found at: http://n.neurology.org/content/81/15/1366.2.full

This article cites 7 articles, 1 of which you can access for free at: http://n.neurology.org/content/81/15/1366.2.full\#ref-list-1

Information about reproducing this article in parts (figures,tables) or in its entirety can be found online at:

http://www.neurology.org/about/about_the_journal\#permissions

Information about ordering reprints can be found online: http://n.neurology.org/subscribers/advertise

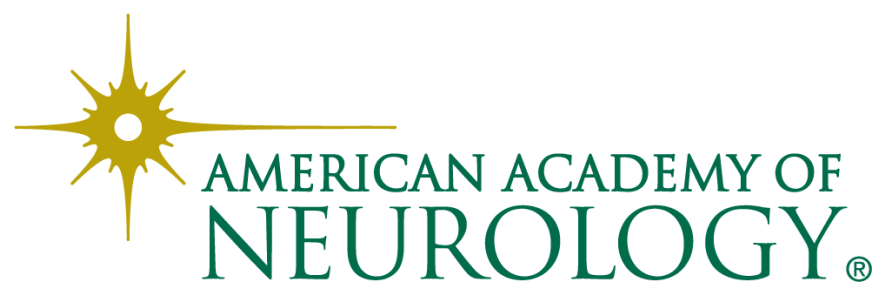

